\title{
Determinants of Full Vaccination Status in Children Attending Immunization Clinic in a Tertiary Hospital in Benin City, Nigeria
}

\author{
UWAIBI, NE \\ Department of Community Health, Edo University, Iyamho, Edo State, Nigeria \\ Correspondence Email: noel.uwaibi@gmail.com
}

\begin{abstract}
Immunization is a cost-effective approach aimed at improving child survival. Coverage is an indicator to monitor the progress towards achieving child survival and the strategy to reduce childhood morbidity and mortality. The study was a descriptive cross-sectional study among 300 mothers /caregivers attending a tertiary institution clinic for immunization of the children using immunization card and verbal response of the mother. Findings from the study showed that $220(73.3 \%)$ of the index children were fully vaccinated for age while 80 $(26.7 \%)$ were not. BCG was the commonest vaccine received by the respondents as $280(93.3 \%)$ received it, followed by OPV, $261(87.0 \%)$ and Pentavalent vaccine, $246(82.0 \%)$. Majority of the index children were vaccinated for age with high BCG, OPV and Pentavalent vaccine coverage rates. Socio-demographic factors that influenced the utilization of immunization included the mothers' level of education, occupation, reception of antenatal care. A better understanding of the immunization schedule is important in the design and implementation of immunization programmes. Educating mothers about vaccines and vaccine preventable diseases are recommended.
\end{abstract}

DOI: https://dx.doi.org/10.4314/jasem.v24i8.12

Copyright: Copyright (C) 2020 Uwaibi. This is an open access article distributed under the Creative Commons Attribution License (CCL), which permits unrestricted use, distribution, and reproduction in any medium, provided the original work is properly cited.

Dates: Received: 30 May 2020; Revised: 03 July 2020; Accepted: 05 August 2020

Keywords: determinants, vaccination, tertiary hospital, childhood

Effective interventions such as immunization, fights common and preventable childhood illnesses, which is considered important for improving child survival. For immunization to be effective as a long-term global childhood disease control strategy, it is essential for parents to continue to present their children for vaccination. (WHO, 2012) Receipt of vaccines at recommended ages and intervals ensures that the child is adequately protected from target diseases at all times. However, to achieve maximal protection against vaccine-preventable diseases, a child should receive all immunizations within recommended intervals as the percentage of children who have received the requisite number of vaccine doses irrespective of the age at receipt of the vaccine determines vaccination coverage. (Luman et al 2005) In Nigeria, routine immunization against the childhood vaccine preventable diseases requires the child to make five visits to a static immunization clinic. At each visit the mother is given appointment dates (written on the child's registration card) for the next vaccination. Despite this approach, noncompliance with immunization schedules by mothers have been reported to be one of the contributory factors to low immunization coverage in Nigeria. (FMOH, 1992; FMOH, 1995). Since Nigeria started its EPI in 1979 (NPI, 2001), Reports have shown that the coverage has been fluctuating especially after the global universal childhood immunization efforts ended in 1990. This could have resulted from poor political will and social support, inadequate funding and poor community involvement and participation. In view of the important need to improve the efficiency of immunization which was declining so fast and also to meet the universal challenges of immunization, to receive one dose of Bacille Calmette Guerin (BCG) and Hepatitis B at birth, three doses of Oral Polio Vaccine (including one IPV), and three doses of Pentavalent vaccine, at six, ten and fourteen weeks and one dose of measles vaccine and yellow fever given at nine months of age.(Adedire et al., 2016) It is recommended that a child should receive all immunization at the appropriate ages and intervals in order to ensure maximal protection from vaccine preventable diseases.(Sadoh and Eregie, 2016)The percentage of children who have receive the requisite number of vaccine doses irrespective of the age at receipt of the vaccine is used to determine vaccination coverage(Abdulraheem et al, 2011)and the third dose of pentavalent vaccine is the key indicator to measure immunization programme coverage.(Matua et al., 2016).The National Demographic and Health Survey (NDHS), 2013 reported that, 25 percent of children were fully vaccinated while $21 \%$ of eligible children 
received no vaccination at all. Fifty-one percent received the $\mathrm{BCG}$ vaccine, $42 \%$ received the measles vaccine, $51 \%$ received the first dose of the DPT vaccine, while only $38 \%$ received the third dose, reflecting a dropout rate of $25 \%$ for DPT. Overall, $21 \%$ of the children received all the recommended vaccinations before their first birthday. However, in Edo State immunization coverage rate in 2013 was put at $52 \%$. Although immunization coverage in Nigeria has improved over the past 10 years, from $13 \%$ in 2003 to $25 \%$ in 2013, it still fell short of the increase needed to achieve the MDG target of more than $90 \%$ coverage. (NDHS, 2013). Several studies on immunization coverage have relied on samples from clinic-base such studies may give biased estimate of immunization levels in the general population. Despite this shortcoming, data collected from clinic-based records can give a substantial insight into the level of immunization coverage and the factors that influence it. This study sought to determine vaccination status, of children attending immunization clinic in a tertiary hospital.

\section{MATERIALS AND METHODS}

This study which utilised a descriptive, cross sectional study design was carried out at the University of Benin Teaching Hospital (UBTH). UBTH is a tertiary health facility in Nigeria, and was established to complement the University of Benin in 1973. UBTH provides secondary and tertiary care to the Edo and Delta States, its environs. It also provides facilities for training of high and middle level manpower for the health industry. UBTH has over 25 Department among which includes the Child Health Department, with a goal of providing the highest level of health care to the largest possible number of children. UBTH is located in Egor LGA, Benin City with a workforce comprising of doctors, nurses, pharmacists, laboratory scientists, social workers, record officers and other administrative staff. A minimum sample size of 300 respondents was obtained using the formula (Cochrane, 1977)

$$
\mathrm{n}=\frac{\mathrm{Z}^{2} \mathrm{Pq}}{\mathrm{d}^{2}}
$$

Where: $\mathrm{n}=$ the minimum sample size required for the study; $\mathrm{P}=$ The proportion of knowledge in mothers in a study done in Enugu, Nigeria $81.2 \%$ of mother's knowledge, perception and practice of childhood immunization. (Tagbo et al, 2012)

Where $\mathrm{q}=1.0-\mathrm{P} ; \mathrm{d}=$ degree of precision at the $0.05 ; \mathrm{z}$ $=$ the standard normal deviate (1.96), which correspond to $95 \%$ confidence interval
Therefore

$$
\mathrm{n}=\frac{(1.96)^{2}(0.81)(0.19)}{0.05^{2}}=236.48
$$

A non-response rate was calculated and added to account for missing or questionnaires not properly filled $\mathrm{n}_{\mathrm{rr}}=$ non response rate $=10 \%=0.1$

$$
\begin{gathered}
n_{f}=\frac{236}{1.0-0.1}=\frac{236}{0.9}=262 \\
n_{i}=262
\end{gathered}
$$

However, 300 respondents were utilised for the study. A systematic random sampling method was used for this study. A list containing the number of children who attend clinic for the past three months was obtained from the matron in charge of the immunization unit at the general practice clinic, this served as the sampling frame. The sampling interval was then obtained using the formula; Total population $/$ sample size $=\mathrm{n}$ (sampling interval). Every $\mathrm{n}^{\text {th }}$ respondent was recruited until sample size was obtained after selecting the first through a random procedure (Balloting) and this was done until the sample size is obtained. Data was collected by use of a researcher administered structured questionnaire, with close and open-ended questions. Variables sought covered the objectives of the study. The questionnaire covered the following areas: Demographic data, parity of mother, age of children, immunization status was evaluated. Thirty questionnaires were pre-tested using mothers attending clinic in the infant well baby clinic at the Central Hospital Benin City, Edo State for clarity, validity and reliability. The questionnaires were screened for completeness by the researcher, screened serially, coded and entered into the Statistical packages for scientific solutions (SPSS) version 21.0 software univariate analysis was done to assess the distribution of variables. The obtained results were presented in prose and tables. Fishers exact and chisquared $\left(\mathrm{x}^{2)}\right.$-test was done whenever the total number of expected cells $<5$ were more than $25 \%$, to determine the association between the groups. Statistical significance was set at $\mathrm{p}-$ value $<0.05$.

Ethical clearance to conduct this research was sought and obtained from the University of Benin Teaching Hospital Research Ethics Committee and permission for the study was sought from the UBTH management, the Head of the Family Medicine Department and the matrons in charge of the immunization services. Written informed consent was obtained from each respondent (care giver) before conducting interviews 


\section{RESULTS AND DISCUSSION}

A total of 300 respondents participated in the study. The mean age was 30.7(5.3) years, the higher proportion 147 (47.7) were aged 25-30 years followed by 97 (32.3) years. A higher proportion were married 289 (96.3) and majority were Christians 277 (92.3).

\begin{tabular}{|c|c|c|}
\hline Variable & Frequency $(n=300)$ & Percent \\
\hline \multicolumn{3}{|l|}{ Age (years) } \\
\hline $19-24$ & 24 & 8.0 \\
\hline $25-30$ & 143 & 47.7 \\
\hline $31-36$ & 97 & 32.3 \\
\hline $37-42$ & 29 & 9.7 \\
\hline$>42$ & 7 & 2.3 \\
\hline \multicolumn{3}{|c|}{ Marital status } \\
\hline Single & 6 & 2.0 \\
\hline Married & 289 & 96.3 \\
\hline Widowed & 2 & 0.7 \\
\hline Separated & 3 & 1.0 \\
\hline \multicolumn{3}{|l|}{ Religion } \\
\hline Christianity & 277 & 92.3 \\
\hline Islam & 20 & 6.7 \\
\hline ATR & 3 & 1.0 \\
\hline \multicolumn{3}{|l|}{ Tribe } \\
\hline Benin & 134 & 44.7 \\
\hline Igbo & 43 & 14.3 \\
\hline Esan & 26 & 8.7 \\
\hline Yoruba & 23 & 7.7 \\
\hline Urhobo & 14 & 4.7 \\
\hline Afemai & 10 & 3.3 \\
\hline Owan & 9 & 3.0 \\
\hline Delta Igbo & 9 & 3.0 \\
\hline Etsako & 8 & 2.7 \\
\hline Isoko & 6 & 2.0 \\
\hline Others* & 18 & 6.0 \\
\hline
\end{tabular}

Two hundred and thirty-six (78.7\%) delivered in a government health facility, $52(17.3 \%)$ gave birth in a private health facility while $12(4.0 \%)$ delivered at home. Two hundred and thirty-three $(77.7 \%)$ attended antenatal clinic while $67(22.3 \%)$ did not. This is shown in table 2

Immunization coverage: Seventy-three (75.3\%) Infants of mothers/caregivers aged $31-36$ years had babies who were fully vaccinated for age compared to $3(42.9 \%)$ of respondents aged above 42 years. There was an increased tendency for the index child to be fully vaccinated with decrease in age of the respondents.

This association was not statistically significant $(\mathrm{p}=$ $0.402)$. Five $(83.3 \%)$ of the single respondents had children who were fully vaccinated for age compared to $210(72.7 \%)$ of the married respondents. This association was also not statistically significant $(\mathrm{p}=$ $0.848)$. Two $(25.0 \%)$ of the respondents with no formal education had children who were fully vaccinated for age compared to $28(96.6 \%)$ of those with tertiary level of education.

Table 2: Place of delivery, attendance of ANC and Sociodemographic characteristics of the index children

\begin{tabular}{lll}
\hline Variable & Frequency $(\mathbf{n}=\mathbf{3 0 0})$ & Percent \\
\hline $\begin{array}{l}\text { Place of delivery } \\
\begin{array}{l}\text { Government health } \\
\text { facility }\end{array}\end{array}$ & 236 & 78.7 \\
$\begin{array}{l}\text { Private health facility } \\
\text { Home }\end{array}$ & 52 & 17.3 \\
$\begin{array}{l}\text { Attendance of ANC } \\
\text { Yes }\end{array}$ & 12 & 4.0 \\
No & 233 & \\
Age (months) & 67 & 77.7 \\
$12-23$ & 163 & 22.3 \\
$24-35$ & 60 & 54.3 \\
$36-47$ & 35 & 20.0 \\
$48-59$ & 42 & 11.7 \\
Number of children & & 14.0 \\
$\leq 4$ & 263 & \\
$>4$ & 37 & 87.7 \\
\hline \multicolumn{2}{c}{ Mean age $=26.3 \pm 13.7$ months }
\end{tabular}

Table 3: Immunization of the index child of the respondents

\begin{tabular}{|c|c|c|}
\hline Variable & Frequency $(n=300)$ & Percent \\
\hline \multicolumn{3}{|c|}{ Fully vaccinated for age } \\
\hline Yes & 220 & 73.3 \\
\hline No & 80 & 26.7 \\
\hline \multicolumn{3}{|l|}{ Vaccines received } \\
\hline $\mathrm{BCG}$ & 280 & 93.3 \\
\hline OPV & 261 & 87.0 \\
\hline Pentavalent vaccine & 246 & 82.0 \\
\hline Measles & 171 & 57.0 \\
\hline Yellow fever & 157 & 52.3 \\
\hline
\end{tabular}

There was an increased tendency to have fully vaccinated children among the more educated respondents. This association was statistically significant $(\mathrm{p}<0.001)$. One hundred and ninety-three $(75.1 \%)$ of the employed respondents had fully vaccinated children compared to $27(62.8 \%)$ of the unemployed respondents. This association was however not statistically significant $(\mathrm{p}=0.091)$. Contrarily, there was a statistically significant association between the occupation of the respondents and the full vaccination of the index child for age $(\mathrm{p}=$ $0.028)$. One hundred and ninety-six $(84.1 \%)$ of the respondents who attended antenatal clinic fully vaccinated the index child for age compared to 24 $(35.8 \%)$ of those who did not attend antenatal clinic. There was an increased tendency to have a fully vaccinated child among those who attended antenatal clinic. This association was statistically significant ( $\mathrm{p}$ $<0.001)$. One hundred and seventy $(72.0 \%)$ of the respondents who delivered in government health facilities had children who were fully vaccinated for age compared to $46(88.5 \%)$ of those who delivered in private health facilities $(\mathrm{p}<0.001)$. There were no statistically significant relationships between the 
number of children and age of the index child with the full vaccination of the index child $(\mathrm{p}=0.213$ and 0.085 respectively). Two hundred and twenty $(73.3 \%)$ of the index children were fully vaccinated for age while 80
(26.7\%) were not. BCG was the commonest vaccine received by the respondents as $280(93.3 \%)$ received it, followed by OPV, $261(87.0 \%)$ and Pentavalent vaccine, $246(82.0 \%)$.

Table 4: Respondents' socio-demographic characteristics and the index child's full vaccination for age

\begin{tabular}{|c|c|c|c|c|c|}
\hline \multirow[t]{2}{*}{ Variable } & \multicolumn{3}{|c|}{ Fully vaccinated for age } & \multirow[t]{2}{*}{ Test statistic } & \multirow[t]{2}{*}{ p value } \\
\hline & Yes n (\%) & No n (\%) & Total n (\%) & & \\
\hline \multicolumn{6}{|l|}{ Age (years) } \\
\hline $19-24$ & $17(70.8)$ & $7(29.2)$ & $24(100.0)$ & \multirow[t]{5}{*}{$\chi^{2}=4.031$} & \multirow[t]{5}{*}{0.402} \\
\hline $25-30$ & $107(74.8)$ & $36(25.2)$ & $143(100.0)$ & & \\
\hline $31-36$ & $73(75.3)$ & $24(24.7)$ & $97(100.0)$ & & \\
\hline $37-42$ & $20(69.0)$ & $9(31.0)$ & $29(100.0)$ & & \\
\hline$>42$ & $3(42.9)$ & $4(57.1)$ & $7(100.0)$ & & \\
\hline \multicolumn{6}{|l|}{ Marital status } \\
\hline Single & $5(83.3)$ & $1(16.7)$ & $6(100.0)$ & \multirow[t]{4}{*}{ Fisher's exact $=1.143$} & \multirow[t]{4}{*}{0.848} \\
\hline Married & $210(72.7)$ & $79(27.3)$ & $289(100.0)$ & & \\
\hline Widowed & $2(100.0)$ & $0(0.0)$ & $2(100.0)$ & & \\
\hline Separated & $3(100.0)$ & $0(0.0)$ & $3(100.0)$ & & \\
\hline \multicolumn{6}{|c|}{ Level of education } \\
\hline No formal & $2(25.0)$ & $6(75.0)$ & $8(100.0)$ & \multirow{4}{*}{$\chi^{2}=134.200$} & \multirow[t]{4}{*}{$<0.001 *$} \\
\hline Primary & $21(26.9)$ & $57(73.1)$ & $78(100.0)$ & & \\
\hline Secondary & $169(91.4)$ & $16(8.6)$ & $185(100.0)$ & & \\
\hline Tertiary & $28(96.6)$ & $1(3.4)$ & $29(100.0)$ & & \\
\hline \multicolumn{6}{|c|}{ Employment status } \\
\hline Employed & $193(75.1)$ & $64(24.9)$ & $257(100.0)$ & \multirow[t]{2}{*}{$\chi^{2}=2.853$} & \multirow[t]{2}{*}{0.091} \\
\hline Unemployed & $27(62.8)$ & $16(37.2)$ & $43(100.0)$ & & \\
\hline \multicolumn{6}{|c|}{ Occupation $(n=257)$} \\
\hline Skill level I & $108(68.8)$ & $49(31.2)$ & $157(100.0)$ & \multirow[t]{4}{*}{ Fisher's exact $=9.085$} & \multirow[t]{4}{*}{$0.028 *$} \\
\hline Skill level II & $73(83.9)$ & $14(16.1)$ & $87(100.0)$ & & \\
\hline Skill level III & $2(100.0)$ & $0(0.0)$ & $2(100.0)$ & & \\
\hline Skill level IV & $10(90.9)$ & $1(9.1)$ & $11(100.0)$ & & \\
\hline \multicolumn{6}{|c|}{ Antenatal clinic attendance } \\
\hline Yes & $196(84.1)$ & $37(15.9)$ & $233(100.0)$ & \multirow[t]{2}{*}{$\chi^{2}=62.076$} & \multirow[t]{2}{*}{$<0.001 *$} \\
\hline No & $24(35.8)$ & $43(64.2)$ & $67(100.0)$ & & \\
\hline \multicolumn{6}{|l|}{ Place of delivery } \\
\hline Government HF & $170(72.0)$ & $66(28.0)$ & $236(100.0)$ & \multirow[t]{3}{*}{$\chi^{2}=16.108$} & \multirow[t]{3}{*}{$<0.001^{*}$} \\
\hline Private $\mathrm{HF}$ & $46(88.5)$ & $6(11.5)$ & $52(100.0)$ & & \\
\hline Home & $4(33.3)$ & $8(66.7)$ & $12(100.0)$ & & \\
\hline \multicolumn{6}{|c|}{ Age of the index child } \\
\hline $12-23$ & $118(72.4)$ & $45(27.6)$ & $163(100.0)$ & $\chi^{2}=6.609$ & 0.085 \\
\hline $24-35$ & $51(85.0)$ & $9(15.0)$ & $60(100.0)$ & & \\
\hline $36-47$ & $22(62.9)$ & $13(37.1)$ & $35(100.0)$ & & \\
\hline $48-59$ & $29(69.0)$ & $13(31.0)$ & $42(100.0)$ & & \\
\hline Number of chil & & & & & \\
\hline$\leq 4$ & $196(74.5)$ & $67(25.5)$ & $263(100.0)$ & $\chi^{2}=1.548$ & 0.213 \\
\hline$>4$ & $24(64.9)$ & $13(35.1)$ & $37(100.0)$ & & \\
\hline
\end{tabular}

Seventy-three $(75.3 \%)$ of the children of respondents aged $31-36$ years were fully vaccinated for age compared to $3(42.9 \%)$ of those aged above 42 years. There was an increased tendency for the index child to be fully vaccinated age with decrease in age of the respondents. This association was not statistically significant $(p=0.402)$. Five $(83.3 \%)$ of the single respondents had children who were fully vaccinated for age compared to $210(72.7 \%)$ of the married respondents. This association was also not statistically significant $(\mathrm{p}=0.848)$. Two $(25.0 \%)$ of the respondents with no formal education had children who were fully vaccinated for age compared to 28 $(96.6 \%)$ of those with tertiary level of education. There was an increased tendency to have fully vaccinated children among the more educated respondents. This association was statistically significant $(\mathrm{p}<0.001)$. One hundred and ninety-three $(75.1 \%)$ of the employed respondents had fully vaccinated children compared to $27(62.8 \%)$ of the unemployed respondents. This association was however not statistically significant $(\mathrm{p}=0.091)$. Contrarily, there was a statistically significant association between the occupation of the respondents and the full vaccination of the index child for age $(\mathrm{p}=$ $0.028)$. One hundred and ninety-six $(84.1 \%)$ of the respondents who attended antenatal clinic fully vaccinated the index child for age compared to 24 $(35.8 \%)$ of those who did not attend antenatal clinic. There was an increased tendency to have a fully 
vaccinated child among those who attended antenatal clinic. This association was statistically significant ( $p$ $<0.001)$. One hundred and seventy $(72.0 \%)$ of the respondents who delivered in government health facilities had children who were fully vaccinated for age compared to $46(88.5 \%)$ of those who delivered in private health facilities $(\mathrm{p}<0.001)$. There were no statistically significant relationships between the number of children and age of the index child with the full vaccination of the index child $(p=0.213$ and 0.085 respectively). The study records high immunization coverage with majority of the index children being fully immunized for age. The exact reason for this high coverage may be due to the increased exposure of these women to health education by health personnel during antenatal and postnatal care. Findings from this study where healthcare workers were the major source of information on immunization support this reason. Another reason that may support this finding from our study is shown by the high proportion women that received antenatal care and also delivered in a government or private hospital. Having delivered in a hospital is significant as information on vaccination is regularly repeated at each visit thus reinforcing the message. This will ultimately improve the knowledge and attitude of caregivers on immunization. The high coverage in this study is in contrast to the national coverage rate for completed vaccines at $25 \%$ and also the Edo State coverage of $52.2 \%$ reported by the NDHS in 2013.(NDHS,2013) Other studies in Nigeria report varying coverage rates.(Abidoye ; Odeyemi, 2012), (Adebayo et al., 2012)This finding is however in contrast to other studies in Southern Nigeria which reported much lower coverage rates.(ADEYINKA ET AL., 2009) It is generally accepted that local coverage rates for most antigens should be $80 \%$ and above at local levels and $90 \%$ at the national level for herd immunity to be acquired against vaccine preventable diseases.(WHO ; UNICEF, 2002) However the slow progress in the National coverage rates between the NDHS 2008 (NDHS, 2008) and that of 2013 (NDHS, 2013) coupled with the lower coverage rate found in this study is a pointer for more efforts to be done in order to achieve of these goals and also reduce the prevalence of childhood mortality caused by vaccine preventable diseases. This study revealed that coverage of BCG was $93.3 \%$ which corresponds with the Edo State coverage rate (93.4\%) in the 2013 NDHS. This is praiseworthy and may be due to the high literacy rate in the state and the corresponding high health seeking behavior. It could also be attributed to the finding that a higher proportion of births occurred in government and private health facilities. The finding is consistent with the findings reported by other studies done in Lagos, (Odusanyan, 2008) Edo (NDHS, 2013) and Bayelsa States. (Itimi et al., 2012) The implication of having these high coverage rates is an increased heard immunity and ultimately the protection of under-five children against vaccine preventable diseases. The coverage rate for Polio was $87.0 \%$ which was similar to the finding in the Lagos study. (Adebayo et al, 2012) This is commendable but is however expected as polio is a menace in Northern Nigeria and completely eradicated in the South. (Gidado et al., 2014) A commonly cited reason for this is the nomadic lifestyle of the Northern Nigerian families. Other barriers to Polio vaccination in Nigeria include continued refusals, lower vaccine efficacy, and instability in worst-affected areas. These can be overcome through sustained commitment from the highest level of government right through to the vaccinator on the streets. Children in northern Nigeria need additional OPV doses as an urgent priority, and improvement of vaccine acceptance will be the key to the programme's success. The Pentavalent vaccine coverage rate was $82.0 \%$ as found in this study. The pentavalent vaccine coverage rate was lower than 98.3\% found in a similar study done in Enugu, Nigeria. (Tagbo et al., 2012) This seems to be higher than that reported in Nigeria studies and other African countries (Itimi et al., 2012; Mangal et al, 2014; Mohammed and Afomsa, 2013; Munthali, 2007). The coverage is key to adequate vaccination coverage in children. The high pentavalent vaccine coverage could partly be due to emerging urbanization with better access to social amenities including health infrastructure/services, mother's/caregiver's knowledge about vaccination services and high sensitization and motivation of the population studied. Also, there is high concentration of health facilities in Benin City including one teaching hospital (University of Benin Teaching Hospital), some private specialist hospitals and government owned immunization centers) as well as high mobilization for routine immunization and supplemental national immunization days by the health workers.

The low coverage rate for measles antigen in this study was $57.0 \%$ which is lower than the coverage rate for Edo State $(76.5 \%)$ but higher than that for Nigeria $(42.0 \%)$ in the 2013 NDHS. This is in consonance with the report of a decreasing trend in coverage rate for vaccines given at older ages compared to those given at younger ages (NDHS, 2013) As immunization compliance reduces as the child matures. This points to the need for a more aggressive approach in the form of health education and follow ups. Three socio demographic characteristics were found to influence whether a child completed WHO routine immunization program in time or not. These are maternal education and occupation. Women with higher level of education as well as women with higher 
occupational class had higher tendency to ensure their children completed routine immunization program within the recommended period relative to mothers with lower level of education and occupational class respectively. This was found in literature. (Adebayo et al., 2012 and Itimi et al., 2012) This finding is also in consonance with studies by Munthali, 2007 in Malawi and Kenya (Kamau and Esamai, 2009) where mothers' education was a major determinant factor of vaccination coverage. The possible explanation for these findings is that women with higher level of education are more informed on importance of child immunizations and are in better position to understand why timing for the immunizations is important. Hence this could be the reason these women are more likely to ensure their children complete routine immunizations in recommended time. This fact highlights the role of female literacy and female education for the utilization of child health services. For mothers in higher occupational classes, these women have access to resources which could be facilitating them to seek Maternal and Child Health $(\mathrm{MCH})$ care as required compared to women who have lower occupational classes due to the higher revenue associated with the former. These findings are supported by other similar studies conducted in developing countries. Maternal education has been found to have the same influence in Northern Nigeria where women with secondary level of education and above were found to be 3 times more likely to ensure their children completed immunization.(Gidado et al, 2014) In Mozambique lack of maternal education was found to be a risk factor for incomplete immunization.(Jani et al., 2008) The latter study concluded that the females who were house wives had less capability to immunize their children as compared to the females who were working. There was an increased tendency for the index child to be fully vaccinated age with decrease in age of the respondents. Babalola in 2008 worked on the household survey of Nigeria and found a positive and significant relationship between child immunization and mother's age. Ibnof, et al, explained that the old mothers were more sensible so they increased the probability of immunizing their children. A higher proportion of the fully vaccinated children were among those delivered in healthcare facilities compared to those who delivered at homes. This could be influenced by the fact that most of the babies received their first doses of vaccinations before discharge following their deliveries in the hospital as well as the fact that caregivers received adequate health education regarding childhood vaccinations. Such findings have been corroborated by other workers. (Belachew and Wakgari, 2012; Mosiur and Sarker, 2010).This underscores the importance of health education as well as training and re-training of healthcare personnel. There was a decreased tendency for the index child to be fully immunized with increase in number of children. First children had less chances of being completely immunized than that of second and third one. It might be because of more sensitization and awareness of parents regarding immunization of second and third child as compared to first due to their previous experiences about it. Significantly lower immunization coverage among children having higher birth order could be explained by the fact that they belonged more likely to lower socioeconomic classes, had less educated or illiterate and working mothers. This is corroborated by other similar studies. (Adebayo et al. 2012) Reasons for dropouts or incomplete vaccinations includes: don't think it necessary, forgetfulness, and child is sick were reported by few of the caregivers. Similar responses have been given in other studies in Nigeria as the causes for the high number of unvaccinated children despite the availability of potent vaccines. (Itimi et al, 2012)The government health facilities, especially at the primary level need to be more user friendly by making it accessible to all and also by reducing the waiting time so that the health system becomes efficient for the achievement of the goal of "Health to All ". The insufficient knowledge of the people requires sincere effort on the part of the health professionals and policy makers to plan and execute the IEC (information, education and communication) initiatives. However, the number of the unvaccinated children as seen in the current study is few compared to findings from other similar works in Nigeria and other parts of sub-Saharan Africa. (CDC, 2014).

\section{REFERENCES}

Abduralheem, I; Omajole, AT; Jimoh, A; Oladipo, AR (2011). Reasons for incomplete vaccination and factors for missed opportunities among rural children. Journal of Public Health and Epidemiology. 3 (4):194-203.

Abidoye AO; Odeyemi KA (2013). Knowledge, attitude and practice of mothers to childhood immunization in Kosofe local government area of Lagos State, Nigeria. IJBAIR. 2(4): $66-72$

Adebayo, BE; Oladokun, RE; Akinbami, FO (2012). Immunization Coverage in a Rural Community in Southwestern Nigeria. J Vaccines Vaccin. 3 (4):16

Adedire, EB; Ajayi, I; Fawole, IO; Ajumobi, O; Kassasa, P (2016). Immunization coverage and its determinants among children aged 12-23 months in 
Atakumosa-West district Osun State Nigeria. BioMed Central Public Health. 16:905

Adeyinka, D; Oladimeji, O; Adeyinka, F; Aimakhu, C (2009). Uptake of Childhood Immunization among Mothers of Under-Five in Southwestern Nigeria. The Internet Journal of Epidemiology. 7(2).

Babalola, S (2008). Determinants of the uptake of the full dose of diphtheria-pertusis-tetanus vaccines (DPT3) in Northern Nigeria: a multilevel analysis. Maternal child Health J.

Belachew, E; Wakgari, D (2012). Factors Associated with Immunization coverage in children aged 12 23 Month in Ambo Woreda, Central Ethiopia. BMC Public Health. 12:566

Centers for Disease Control and Prevention (2014) Global Routine Vaccination, 2010. Morbidity and Mortality Weekly Report (MMWR). 60: 15201522.

Cochrane WG. Sampling Techniques, 3rd Edition. New York: John Wiley and Son 1977.

Federal Ministry of Health, Nigeria (1992). National immunization coverage survey. Nig Bull Epidemiol. 2: 3-9.

Federal Ministry of Health, Nigeria (1995). National Immunization Policy and Standard Practice. 2: 220.

Gidado, S; Nguku, P; Biya, O; Waziri, NE; Mohammed, A; Nsubuga, P (2014). Determinants of routine immunization coverage in Bungudu, Zamfara State, Northern Nigeria. Pan Afr. Med. J. 18 (1): 9.

Ibnouf, AH; Borne, VD; Jam, M (2007). Factors influencing immunization coverage among children under five years of age in Khartoum State, Sudan. SA Fam. Pract. 49(8):14.

Itimi, K; Dienye, PO; Ordinioha, B. Community participation and childhood immunization coverage (2012). A comparative study of rural and urban communities of Bayelsa State, South-south Nigeria. Niger. Med. J. 53(1):21-5.

Jani, JV; De Schacht, C; Jani, IV; Bjune, G (2008). Risk factors for incomplete vaccination and missed opportunity for immunization in rural Mozambique. BMC Public Health. 8; 161.
Kamau, N; Esamai, FO (2009). Determinants of Immunization Coverage among Children in Mathare Valley, Nairobi. East African Medical Journal. 86: 323-329

Luman, ET; Barker, LE; Shaw, KM; Mccauley, MM; Buehler, JW; Pickering, LK (2005). Timeliness of childhood vaccinations in the United States. J. Am. Med. Assoc.293:1204-1211.

Mangal, TD; Aylward, RB; Mwanza, M; Gasasira, A; Abanida, E; Pate, MA (2014). Key issues in the persistence of poliomyelitis in Nigeria: a casecontrol study. The Lancet Global Health. 2 (2): 9097

Matua, MK; Kimani-Murage, E; Ngomi, N; Ravn H; Mwaniki, P; Echoka, E (2016). Fully immunized child; coverage, timing and sequencing of routine immunization in urban poor settlement in Nairobi, Kenya. Tropical Medicine and Health. 44 (13):112.

Mohammed, H; Afomsa, A (2013). Assessment of Child Immunization Coverage and Associated Factors in Oromia Regional State, Eastern Ethiopia. Science, Technology and Arts Research Journal. 2: 36-41

Mosiur, R; Sakar, ON (2010). Factors Affecting Acceptance of Complete Immunization Coverage of Children under Five Years in Rural Bangladesh. Salud Pãblica de Mãxico. 52, 134-140.

Munthali, AC (2007). (Determinations of Vaccination Coverage in Malawi: Evidence from the Demographic and Health Surveys. Malawi Medical Journal. 19: 79-82.

National Population Commission and ICF International. Nigeria Demographic and Health Survey (2013). Abuja, Nigeria: NPC and ICF International. 92-153

Nigeria Demographic and Health Survey (2008). National Population Commission (Nigeria) and ORC Macro. Calverton, Maryland: USAID. 20-22.

Odusanya, OO; Alufohai, EF; Meurice, FP; Ahonkhai, VI (2008). Determinants of vaccination coverage in rural Nigeria. B.M.C. Public Health. 381 (8): $1471-2458$

Sadoh, AE; Eregie, OC (2009). Timeliness and Completion Rate of Immunization among Nigerian 
children attending a clinic-based Immunization service. J Health Popul Nutr. 27(3):391-395

Tagbo, BN; Uleanya, ND; Nwokoye, IC; Eze, JC; Omotowo, IB; Uleanya, ND. (2012). Mothers' knowledge, perception and practice of childhood immunization in Enugu, Niger J Paed. 39 (3):90 96
WHO and UNICEF (2002) State of the World's Vaccines and Immunization? Geneva.

World Health Organization (WHO) Immunization, vaccines and biologicals. 10 facts on immunization. $\quad 2012 \quad$ Available at http://www.who.int/features/factfiles/immuniza tion/facts/en/index.html 